\title{
SHEFFIELD LABORATORIES OF THE BRITISH IRON AND STEEL RESEARCH ASSOCIATION
}

\section{OPEN DAYS}

\begin{abstract}
$\mathrm{T}$ HE Sheffield laboratories of the British Iron and Steel Research Association are concerned mainly with research on steelmaking, metal working and ferrous metallurgy and are also a base for a section which deals with technicel inquiries and investigations on the uses of iron and steel. They form one of the Association's five establishments : research on ironmaking, engineering, metal surfaces and coatings, with supporting departments of physics, chemistry and operational research, is done in London, Swansea and Middlesbrough, and the administrative headquarters are in London.

Open days were held at the Sheffield laboratories during September 6-7, when the opportunity was taken by a large number of visitors to view the work going on there. In the same building, and sharing the Association's general services, are three autonomous co-operative research organizations: the Cutlery Research Council, File Research Council and the Coil Spring Federation Research Organization.
\end{abstract}

\section{Steelmaking}

The Steelmaking Division is concerned with the hot metal when it leaves the blast furnace and until it has been turned into ingots. Current researches deal with the operation of open-hearth furnaces and electric-arc furnaces, the chemistry of steelmaking in each, and the problems of ingots and ingot moulds. Considerable emphasis is placed on the combustion problems of open-hearth furnaces, which produce about 90 per cent of steel in Great Britain. Research in the Association has shown what are the essentials of good burner design, and this knowledge is being widely used in the industry. Sulphur pick-up from the fuel and heat transfer are being studied on a $1 / 12$ scale open-hearth furnace model.

The melting shop at the Association's laboratories houses a 10-cwt. basic electric-arc furnace, which has been used for studying the effects of different power inputs, changing the diameter of the electrodes, the height of the furnace, etc. Other work is concerned with desulphurization and close contact is kept with the more fundamental work on slag-metal reactions in the electric proeess, which is being carried out in London. The way in which mould dressings work has been observed by high-speed photography through a 'Pyrex' plate let into the side of a mould, and the properties needed in a mould dressing to give a good surface to the ingot have been determined.

During recent years, processes for continuous casting have been developed rapidly, and at least four experimental plants are working in Britain, two of which use a method patented by the Association. Research on the continuous-casting plant at the Sheffield laboratories includes the effects on quality of cooling-rate and of speed and temperature of casting.

\section{Metal Working}

The Mechanical Working Division is concerned with forming processes by which the ingot is made into a finished product. The processes comprise rolling, forging, extrusion, wire drawing and sheet metal working. The research also covers the plant and tools of metal working, and the mechanical properties of the products. Among recent and current work, prominence has been given to lines of research of immediate interest to the industry, and some important practical achievements are already claimed.

In rolling, much of the research has been, and is being, devoted to the automatic control of the thickness of strip being rolled. The Association holds several patents in this field, and last year the first industrial installation of its 'setting' method of automatic control of strip gauge was put into operation on a reversing cold-strip mill at the Lancashire and Corby Manufacturing Co. by the Davy and United Engineering Co. ; several other installations at home and abroad are in hand. Current research is devoted to the operation of 'tandem' mills used, for example, in the manufacture of tinplate and motor-car bodies; a model three-stand mill has been built for the purpose, with some novel features incorporated.

Investigations of the reheating of ingots and billets for forging have led to significant improvements of present practices in heating. For example, cast ingots of high-speed tool steel can now be heated in an hour or less, as against overnight heating hitherto practised. Among results of recent industrial applications of this are a 25 per cent saving of fuel, a 50 per cent reduction of scale loss, and the elimination of decarburization. Attention is now being given to the mechanization of forging and the improvement of the control of forging plant. The 200-ton laboratory press has been fitted with a position-control system developed by the Association whereby forging is made more speedy and accurate.

In wire drawing, an invention by Prof. D. G. Christopherson of a method for inducing hydrodynamic lubrication has been adapted by the Association to conventional soap-powder lubrication. Full-scale trials in wire mills are more than fulfilling expectations, since dies last twice to ten times ws long as previously. In another method, the wire is electroplated during drawing with a thin film of lubricant, which is transparent so as to preserve the high finish required for some applications.

Many other investigations are in progress. The stress-strain characteristics of a dozen steels at high temperatures and rapid rates of deformation have been determined for the calculation of rolling loads in hot rolling. Small steel bars are rolled experimentally as part of investigations into the mechanics of the rolling of sections. The causes of stretcherstrain markings and the mechanisms of their suppression by temper rolling, roller and stretch-levelling have been studied and are now understood more completely. The Swift test of the suitability of sheet metal for drawing and pressing has been further developed. The influence of tool geometry on the mechanical properties of finished forgings has been studied. Experimental investigations have been made of die pressure and drawing force, and of the temperatures in the interior of the die at the interface between the die and wire. 


\section{Metallurgy}

The Metallurgy (General) Division deals essentially with the treatment, properties and uses of iron and steel. A considerable amount of the work is done extra-murally in university and government labora. tories, or collaboratively in the works and laboratories of member firms, but specialist teams in the Divisional Laboratory deal with particular aspects of the work.

Theory suggested that stretcher-strain markings on steel sheet, when deep-drawn or pressed, were produced by the diffusion of nitrogen and carbon through the material. Experiments have confirmed the theory, and have shown that nitrogen has a worse effect than carbon. Transformer laminations are usually made of iron containing 3-4 per cent of silicon. Its magnetic properties are seriously affected. by small amounts of impurities, particularly nitrogen. Keducing the nitrogen content of very pure siliconiron from $0 \cdot 007$ to $0 \cdot 004$ per cent saved rather more than 10 per cent of the total losses, and the effects of additions of nitrogen are much the same in commercial material. The strength, energy and mobility of grain boundaries, which control such properties as brittleness, transformations and recrystallization of metals, are being explored by measurements of internal friction. Work is being done to improve the structure of high-speed tool steels.

Fatigue research was undertaken to determine statistically the variation in fatigue properties of wrought material from different ingots and from different ports of the same ingot for two different casts of steel. Statistically significant variations in properties have been found, but these are not thought to be of practical importance. Further work is in hand with a very-high-tensile steel. Increasing importance is being given to the production, in large quantities, of mild steel having a high resistance to brittle fracture. The effect of variations in rolling conditions, such as variation in the finishing temperatures of rolling, rolling schedules, etc., is being studied.

The analytical section provides a service to the whole Association and also undertakes analytical research. Special methods have often to be developed, for example, for the determination of trace elements, or when only very small samples are available. The characteristics of spectrographic source units and the sensitivity and reproducibility of analysis under various arc-like and spark-line conditions have been studied for a large number of elements normally present in steels.

\section{Steel Users}

The Steel Users Section of the Association is mainly responsible for answering technical inquiries on the uses of steel, undertaking ad hoc and shortterm investigations concerning uses of steel and maintaining contact with the smaller member firms of the Association. Typical work concerns the establishment of the optimum heat-treatment procedure for the manufacture of specific products, investigations of obscure difficulties, and advice on matching the performance of components with steel specifications.

\section{Associated Research Councils}

The Cutlery Research Council is an autonomous and independently financed co-operativo research organization formed in 1951 to work for members of the Sheffield Cutlery Manufacturers' Association. Its work is organized and controlled by the cutlery industry, but its staff are in close and constant collaboration with the British Iron and Steel Research Association, which provides services, background information on steels, and general assistance. At present the main research projects of the Council are: to improve methods for the production of blanks; to study cutting edges; and to study the grinding and polishing processes used in finishing cutlery. There is also a technical inquiry service, which gives confidential technical assistance to individual manufacturers on application.

The File Research Council is another autonomous and independently financed co-operative research organization formed in 1955 to work for members of either the File Trade Association or the File Manufacturers' Association. The unit is controlled by its member firms, but there is close collaboration with the British Iron and Steel Research Association, which provides services, background information on steel and general assistance. In addition to confidential technical inquiry facilities the Council has begun work on the metallurgy of file steels with particular reference to methods of heat treatment and on testing methods for both saw and engineers' files. The shapes of file teeth and methods of producing a desired shape are also being studied.

The Coil Spring Federation Research Organization has only recently taken over laboratory space at Sheffield; it is in the process of being equipped and expects to undertake active research work in the near future.

\section{OBITUARIES}

\section{Prof. Walther Kossel}

WALther Kossel, who died after a long illness on May 22, was one of Germany's outstanding physicists, both as a theorist and as an experimenter. He was born on January 4, 1888, into a family that included many men distinguished for their learning. In particular, his father, Albrecht Kossel, was a famous physiologist, long professor at Heidelberg. A students' torch-light procession in his honour, on the occasion of his being awarded the Nobel Prize in Physiology and Medicine, was one of the events during the time when Walther was working for his doctorate in Lenard's laboratory at Heidelberg.
After taking his doctorate in 1911, Kossel moved to Munich, where the University and Technische Hochschule numbered many names renowned in the physical sciences: men such as Arnold Sommerfeld, Max von Laue and Jonathan Zenneck, as well as the world-famous Röntgen. In this stimulating atmosphere he produced work of prime importance on the electronic structure of the nuclear atom, which was then in active development. In particular he dealt with the theory of X-ray emission and absorption, explaining for the first time the mechanism of excitation of the different series and the fine structure of the absorption edges in terms of the Bohr atom. Equally 